\title{
Differential responsiveness to cigarette price by education and income among adult urban Chinese smokers: findings from the ITC China Survey
}

\author{
Jidong Huang, ${ }^{1}$ Rong Zheng, ${ }^{2}$ Frank J Chaloupka, ${ }^{1,3,4}$ Geoffrey T Fong, ${ }^{5,6,7}$ Yuan Jiang ${ }^{8}$
}

\begin{abstract}
${ }^{1}$ Health Policy Center, Institute for Health Research and Policy, University of Illinois at Chicago, Chicago, Illinois, USA ${ }^{2} S$ chool of International Trade and Economics, University of International Business and Economics, Beijing, China ${ }^{3}$ Health Policy Center, Institute for Health Research and Policy, University of Illinois at Chicago, Chicago, Illinois, USA ${ }^{4}$ WHO Collaborating Centre on the Economics of Tobacco and Tobacco Control

${ }^{5}$ Department of Psychology, University of Waterloo, Waterloo, Ontario, Canada ${ }^{6}$ Ontario Institute for Cancer Research, Toronto, Ontario, Canada

${ }^{7}$ School of Public Health and Health Systems, University of Waterloo, Ontario, Canada

${ }^{8}$ Chinese Center for Disease Control and Prevention, Beijing, China
\end{abstract}

\section{Correspondence to} Dr Jidong Huang, Health Policy Center, Institute for Health Research and Policy, University of Illinois at Chicago, 1747 West Roosevelt Rd, Chicago, IL 60608, USA;

jhuang12@uic.edu

Received 9 October 2014 Accepted 6 March 2015 Published Online First 8 April 2015

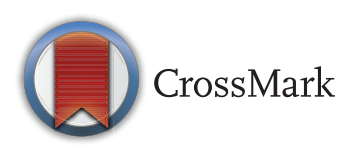

To cite: Huang J, Zheng $\mathrm{R}$, Chaloupka FJ, et al. Tob Control 2015;24:iii76-iii82.

\section{ABSTRACT}

Background Few studies have examined the impact of tobacco tax and price policies in China. In addition, very little is known about the differential responses to tax and price increases based on socioeconomic status in China.

Objective To estimate the conditional cigarette consumption price elasticity among adult urban smokers in China and to examine the differential responses to cigarette price increases among groups with different income and/or educational levels.

Methods Multivariate analyses employing the general estimating equations method were conducted using the first three waves of the International Tobacco Control (ITC) China Survey. Analyses based on subsample by education and income were conducted.

Findings Conditional cigarette demand price elasticity ranges from -0.12 to -0.14 . No differential responses to cigarette price increase were found across education levels. The price elasticity estimates do not differ between high-income smokers and medium-income smokers. Cigarette consumption among low-income smokers did not decrease after a price increase, at least among those who continued to smoke.

Conclusions Relative to other low-income and middleincome countries, cigarette consumption among Chinese adult smokers is not very sensitive to changes in cigarette prices. The total impact of cigarette price increase would be larger if its impact on smoking initiation and cessation, as well as the price-reducing behaviours such as brand switching and trading down, were taken into account

\section{BACKGROUND}

Tobacco-caused diseases and mortality impose tremendous health and economic costs on China, the world's largest producer and consumer of tobacco. ${ }^{1-5}$ With more than 300 million smokers, China manufactures and consumes one-third (approximately 2.5 trillion cigarettes) of the world's annual cigarette production. ${ }^{6}$ The number of deaths attributed to tobacco use in China has now reached 1.2 million annually, and is projected to rise to 2 million by the year $2025 .^{2}{ }^{3}$ Meanwhile, the economic cost of smoking has increased from $\$ 17.1$ billion in 2003 to $\$ 28.9$ billion in 2008 in China. ${ }^{45}$

Several decades of research has established that significantly increasing tobacco product excise taxes and prices is one of the most effective ways to reduce tobacco use, and tobacco-caused health and economic burdens. ${ }^{7}$ In addition, studies have also found that smokers of different socioeconomic status (SES) tend to have differential responses to cigarette tax and price increases. ${ }^{8}$ This differential responsiveness to price change based on SES can also serve as an important avenue to reduce tobacco use, particularly among those who are most sensitive to cigarette price increases.

Unfortunately, with the exception of the 2009 tobacco tax adjustment, China has not increased its tobacco tax since it signed onto the WHO Framework Convention on Tobacco Control in 2003. Cigarette taxes in China today account for slightly over $40 \%$ of retail prices, far below the world median level of $65-70 \% .^{9}$ One of the factors that might contribute to this inaction is the lack of certainty among policymakers in projecting the impact of cigarette tax increase on cigarette consumption, smoking prevalence, government tax revenue and tobacco-related employment, which is, in part, due to the paucity of China-specific studies that examine the effectiveness of tobacco tax/price and differential responses among smokers in China. To date, there have only been a handful of studies that examined the impact of tobacco tax/price policies in China. ${ }^{9-17}$

Moreover, very little is known about the differential responsiveness to tax and price increases based on SES in China. We are only aware of two studies that looked at price elasticity estimates by income levels. Mao et $a l^{17}$ used a national tobacco consumption survey and found higher price elasticity is associated with the low-income group. Mao et $\mathrm{al}^{16}$ estimated the overall price elasticity of cigarettes $(-0.5)$, at various income levels (at poverty level, -1.9; low-income, -0.8 ; high-income, -0.5 ), using individual level data from 16 counties in China in 1998.

Building on these seminal studies, this paper aims to estimate the price elasticity for cigarette consumption among adult smokers in China using individual level longitudinal survey data. It will also examine the differential responses to cigarette price increases among groups with different income and/ or educational levels. This paper contributes to the literature as follows: unlike previous studies relying on aggregated sales data or cross-sectional microlevel data, we use individual level multiwave longitudinal data to examine the impact of cigarette prices on cigarette consumption in China, which allow us to look at how the same individuals alter their cigarette consumption as cigarette prices change over time. Additionally, this paper pushes the envelope on what is known about the effect of cigarette price in China by examining the differential responsiveness to cigarette price increases based on income and educational levels. 


\section{METHODS}

\section{Data}

The analyses in this paper rely on the International Tobacco Control (ITC) Policy Evaluation Project-China Surveys (the ITC China Survey). The ITC China Project, established in 2006, is a longitudinal cohort survey conducted in seven cities in China (Beijing, Changsha, Guangzhou, Kunming, Shanghai, Shenyang and Yinchuan). These seven cities differ in their population sizes, areas and levels of economic development. They are located in different geographic regions in China, and are good representatives of China's urban areas. Approximately 800 adult (aged 18 and above) smokers are recruited by probability sampling methods in each city. Respondents lost to attrition are replaced with comparable respondents so as to maintain city level representative samples. The retention rate of the ITC China survey was high, more than $80 \%$. More detailed information on the ITC China survey sampling methodology can be found in Wu et al. ${ }^{18}$

This study utilised the first three waves of the ITC China Surveys, conducted in 2006, 2007/2008 and 2009/2010, respectively. The sample consisted of approximately 2400 observations from each city (800 smokers in each wave) with the exception of Kunming, which was added to the ITC China Survey in the third wave, with only 800 smokers. Because of the missing values (including nonresponses and refusals) in the key outcome variables, the final analytical sample consisted of approximately 13700 smokers.

\section{Measures}

Dependent variable

The dependent variable in our study is cigarette consumption, which measures the average number of cigarettes consumed per day (CPD) by a smoker. This variable is derived from the ITC China survey questions that asked about the number of cigarettes smoked per day for daily smokers, and the number of cigarettes smoked per week for non-daily smokers. For nondaily smokers, the number of cigarettes smoked per week was converted into the average number of cigarettes CPD. Because the distribution of CPD was skewed, this measure was log transformed in the analyses.

\section{Explanatory variables}

The key explanatory variable in this study is the price of a pack of cigarettes. The ITC China Survey asked smokers about their most recent cigarette purchase experience; in particular, how many cartons/packs of cigarettes they purchased and how much they paid in total. Based on the responses to those questions, we first constructed a measure of the selfreported price for a pack of cigarettes, derived from the total amount of money paid and the total number of packs bought in the most recent cigarette purchase. While the self-reported cigarette price is useful in understanding smokers' purchase behaviour, it can reflect endogenous choices of cigarette brands, quality and/or purchase methods. In other words, individuals exercise some choice over the price they pay for cigarettes, rather than the price they pay being determined exogenously. For example, ceteris paribus, heavy smokers may be more likely to smoke cheaper brands of cigarettes, purchase cigarettes in greater quantities, look for lower priced retailers and/or take advantage of price promotions, than individuals who smoke fewer cigarettes. As a result, the selfreported price can be correlated with unobserved differences in preferences and may be endogenous. Consequently, treating an individual's self-reported price as an exogenous variable when examining his or her cigarette consumption will lead to an over (and biased) estimate of the impact of price on reported cigarette consumption. To address this issue, we constructed an aggregated price measure at the city district level, which averaged the self-reported price of a pack of cigarettes among all smokers living in the same district in a city in a given survey wave. This price measure was subsequently adjusted for inflation using 2010 as the base year.

In addition to the cigarette price variable, we also included a number of key demographic and socioeconomic individual (or household) level characteristics such as age, gender, education, family income, marital status and employment status, as well as interview waves/years and city. Specifically, age was grouped into 18-24, 25-39, 40-54 and 55 years or older. Marital status was classified as: married; divorced, separated or widowed; and single. Education level was classified into three categories: less than high school, high school and postsecondary education. Monthly household income was classified into three categories based on the cut-offs for urban areas, from the 2010 China Statistics Yearbook: low-income level $(<¥ 1000)$, medium income level (¥1000-2999) and high income level ( $¥ ¥ 3000)$. Employment status was grouped into employed, unemployed and retired.

\section{STATISTICAL METHODOLOGY}

To estimate the cigarette demand function conditional on being a smoker, we estimated the following models:

$$
\begin{aligned}
\operatorname{Ln}\left(Q_{i j t}\right)= & \beta_{0}+\beta_{1} \operatorname{Ln}\left(P_{d j t}\right)+\beta_{2} E_{i j t}+\beta_{3} I N C_{i j t} \\
& +\beta_{4} X_{i j t}+s_{i t}+y_{i j}+e_{i j t}
\end{aligned}
$$

$\operatorname{Ln}\left(Q_{i j t}\right)$ is the average number of cigarettes CPD by the $i_{\text {th }}$ individual in the $j_{\text {th }}$ city in interview wave/year $t$, in log form. $\operatorname{Ln}\left(\mathrm{P}_{\mathrm{djt}}\right)$ is inflation adjusted average price of a pack of cigarettes in the $d_{t h}$ district in the $j_{\text {th }}$ city in interview wave/year $t$, also in log. $\mathrm{ED}_{\mathrm{ijt}}$ and $\mathrm{INC}_{\mathrm{ijt}}$ represent, respectively, the education and income level for the $i_{\text {th }}$ individual in the $j_{\text {th }}$ city in interview wave/year t. $\mathrm{X}_{\mathrm{ijt}}$ is a vector of individual demographic and socioeconomic characteristics such as age, gender, marital status and employment status. $s_{i t}$ is city indicator for $\mathrm{i}_{\text {th }}$ individual in interview wave/year $t . \mathrm{y}_{\mathrm{ij}}$ is interview wave/ year indicator for $i_{\text {th }}$ individual in the $j_{\text {th }}$ city. And $e_{i j t}$ is the idiosyncratic error term.

Because the ITC China Survey data are longitudinal in nature, errors are correlated within observations across waves for the same individual. As a result, the equation (1) was estimated using the general estimating equations (GEE) method (STATA V.12 xtgee command), which took into account the correlation in error terms among the same respondent across different interview waves. Because of the nature of the cigarette consumption variable, which is continuous, equation (1) was estimated using GEE model with an identify link, with no preimposed assumption on the structure of the covariance matrix of the error terms. Equation (1) was first estimated using the whole ITC China Survey sample (results shown in table 2), it was then estimated using the subsamples by income level (table 3) and education level (table 4) to examine the potential differential responses to cigarette price changes by SES. 
To test whether there were any differential price responses by SES, we estimated the following models:

$$
\begin{aligned}
\operatorname{Ln}\left(\mathrm{Q}_{\mathrm{ijt}}\right)= & \alpha_{0}+\alpha_{1} \operatorname{Ln}\left(\mathrm{P}_{\mathrm{djt}}\right)+\alpha_{2} \mathrm{ED}_{\mathrm{ijt}}+\alpha_{3} \operatorname{Ln}\left(\mathrm{P}_{\mathrm{djt}}\right) \times \mathrm{ED}_{\mathrm{ijt}} \\
& +\alpha_{4} \mathrm{INC}_{\mathrm{ijt}}+\alpha_{5} \mathrm{X}_{\mathrm{ijt}}+\mathrm{s}_{\mathrm{it}}+\mathrm{y}_{\mathrm{ij}}+\mathrm{e}_{\mathrm{ijt}} \\
\operatorname{Ln}\left(\mathrm{Q}_{\mathrm{ijt}}\right)= & \gamma_{0}+\gamma_{1} \operatorname{Ln}\left(\mathrm{P}_{\mathrm{djt}}\right)+\gamma_{2} \mathrm{INC}_{\mathrm{ijt}}+\gamma_{3} \operatorname{Ln}\left(\mathrm{P}_{\mathrm{djt}}\right) \times \mathrm{INC}_{\mathrm{ijt}} \\
& +\gamma_{4} \mathrm{ED}_{\mathrm{ijt}}+\gamma_{5} \mathrm{X}_{\mathrm{ijt}}+\mathrm{s}_{\mathrm{it}}+\mathrm{y}_{\mathrm{ij}}+\mathrm{e}_{\mathrm{ijt}}
\end{aligned}
$$

$\operatorname{Ln}\left(P_{\mathrm{djt}}\right) \times \mathrm{ED}_{\mathrm{ijt}}$ is the interaction term between cigarette price and education levels. $\operatorname{Ln}\left(\mathrm{P}_{\mathrm{djt}}\right) \times \mathrm{INC}_{\mathrm{ijt}}$ is the interaction term between cigarette price and income levels. The estimated coefficient $\alpha_{3}$ and $\gamma_{3}$ in equation (2) and (3) will reveal whether any differential price responses by income and education levels exist. Results from equation (2) and (3) are presented in table 2 (model 4-7).

\section{RESULTS}

\section{Descriptive statistics}

Table 1 contains the descriptive statistics for the key variables used in this study. The calibration of the sample means used standard complex survey post-stratification techniques for variance estimation, which took into account the complex survey/ sampling strategies of the ITC China Surveys. In addition, those statistics were properly weighted using the sampling weights, described fully in the weighting methodology available at http:// www.itcproject.org. Our smoker sample was evenly distributed across interview waves and cities, with the exception of the city of Kunming, which was added in the third wave. The urban smokers in our sample were predominantly male (95\%). The age distribution in our sample was skewed towards adults at prime and mature ages, with $18 \%$ of the smokers aged between 25 and 39, 46\% aged 40-54, 34\% aged 55 years and above, and with only about $2 \%$ being young adults (aged 18-24 years). Eighty-eight per cent of smokers were married at the time of the survey. Forty-three per cent of the smokers reported to have an average family income per month between ¥1000-2999. Fifteen per cent of smokers’ family income was below $¥ 1000$ per month and about $36 \%$ had income of more than $¥ 3000$ per month; the remaining $6 \%$ of smokers' family income information was missing. Thirteen per cent of smokers reported having less than a high school education, 65\% reported having completed high school, and about $21 \%$ of smokers reported having some schooling beyond high school, which included 2 years of college. The average number of cigarettes smoked per day among the ITC China Survey respondents was 17, with some respondents reporting smoking as many as five packs of cigarettes (or 100 cigarettes) per day. The inflation adjusted city district level average price for a pack of cigarettes was $¥ 6.5$, or approximately 1 US dollar per pack.

\section{Multivariate analyses results}

Table 2 presents the results for equations (1)-(3) using the GEE methods, examining the impact of cigarette price on cigarettes smoked per day, as well as the demographic and SES factors associated with cigarette consumption among adult urban Chinese smokers. Model 1 controlled for income and education levels. Model 2 controlled for income but not education, and model 3 controlled for education but not income. Model 4-7

\begin{tabular}{|c|c|c|c|}
\hline Variables & Observation & $\begin{array}{l}\text { Mean/ } \\
\text { proportion }\end{array}$ & \\
\hline \multicolumn{4}{|l|}{ Cigarette consumption } \\
\hline Cigarette consumption per day & 14505 & 17.12 & $(0.1$ to -100$)$ \\
\hline $\begin{array}{l}\text { Ln (cigarette consumption } \\
\text { per day) }\end{array}$ & 14460 & 2.61 & $(-2.3$ to -4.6$)$ \\
\hline \multicolumn{4}{|l|}{ Cigarette price } \\
\hline $\begin{array}{l}\text { Inflation adjusted cigarette per } \\
\text { pack price }\end{array}$ & 13950 & 6.51 & (0.2 to -92.55$)$ \\
\hline Ln(cigarette price) & 13950 & 1.71 & $(-1.61$ to -4.54$)$ \\
\hline \multicolumn{4}{|l|}{ Gender } \\
\hline Female & 14561 & 0.04 & \\
\hline \multicolumn{4}{|l|}{ Age } \\
\hline Aged 18-24 & 14561 & 0.02 & \\
\hline Aged 25-39 & 14561 & 0.18 & \\
\hline Aged 40-54 & 14561 & 0.46 & \\
\hline Aged 55+ & 14561 & 0.34 & \\
\hline \multicolumn{4}{|l|}{ Marital status } \\
\hline Married dummy & 14514 & 0.88 & \\
\hline Single dummy & 14514 & 0.05 & \\
\hline Divorced/widowed dummy & 14514 & 0.06 & \\
\hline \multicolumn{4}{|l|}{$\begin{array}{l}\text { Average total household income } \\
\text { per month (in } ¥ \text { ) }\end{array}$} \\
\hline$\geq 3000$ (high income) & 14561 & 0.35 & \\
\hline 1000-2999 (medium income) & 14561 & 0.43 & \\
\hline$<1000$ (low income) & 14561 & 0.15 & \\
\hline Missing-income dummy & 14561 & 0.07 & \\
\hline \multicolumn{4}{|l|}{ Education } \\
\hline College and above & 14510 & 0.21 & \\
\hline High school & 14510 & 0.65 & \\
\hline Less than high school & 14510 & 0.13 & \\
\hline \multicolumn{4}{|l|}{ Employment status } \\
\hline Employed dummy & 14509 & 0.59 & \\
\hline Unemployed dummy & 14509 & 0.14 & \\
\hline Retired dummy & 14509 & 0.27 & \\
\hline \multicolumn{4}{|l|}{ Interview waves and cities } \\
\hline Wave 1 dummy & 14561 & 0.32 & \\
\hline Wave 2 dummy & 14561 & 0.32 & \\
\hline Wave 3 dummy & 14561 & 0.36 & \\
\hline City Beijing dummy & 14561 & 0.16 & \\
\hline City Shenyang dummy & 14561 & 0.16 & \\
\hline City Shanghai dummy & 14561 & 0.16 & \\
\hline City Changsha dummy & 14561 & 0.15 & \\
\hline City Guangzhou dummy & 14561 & 0.16 & \\
\hline City Yinchuan dummy & 14561 & 0.16 & \\
\hline City Kunming dummy & 14561 & 0.05 & \\
\hline
\end{tabular}
included the interaction terms between cigarette price and income (model 4 and 5), and the interaction term between
Table 1 Descriptive statistics

cigarette price and education (model 6 and 7). Regardless of the model specifications, the overall conditional cigarette consumption price elasticity was consistently shown to be in a narrow range of -0.12 to -0.14 , implying that a $10 \%$ increase in cigarette price would result in a reduction in cigarette consumption among adult urban Chinese smokers by $1.2-1.4 \%$. In the models with interaction terms between cigarette price and income/education, none of the estimated coefficients for the interaction terms were statistically significant, with the exception of the coefficient for the interaction term between cigarette price and low income, which was marginally significant. These results imply that the conditional cigarette consumption price elasticities do not differ across education levels among adult 
Table 2 Conditional cigarette consumption price elasticities among smokers (whole sample)

\begin{tabular}{|c|c|c|c|c|c|c|c|}
\hline Ln(cigarettes) & Model 1 & Model 2 & Model 3 & Model 4 & Model 5 & Model 6 & Model 7 \\
\hline $\operatorname{Ln}$ (price) & $\begin{array}{l}-0.126^{* * *} \\
(0.019)\end{array}$ & $\begin{array}{l}-0.141 * * * \\
(0.019)\end{array}$ & $\begin{array}{l}-0.118^{* * *} \\
(0.019)\end{array}$ & $\begin{array}{l}-0.127^{* * *} \\
(0.019)\end{array}$ & $\begin{array}{l}-0.141^{* * *} \\
(0.019)\end{array}$ & $\begin{array}{l}-0.127^{* * *} \\
(0.019)\end{array}$ & $\begin{array}{l}-0.119 \text { *** } \\
(0.019)\end{array}$ \\
\hline Ln(price) and low-income interaction & & & & $\begin{array}{l}0.181^{*} \\
(0.081)\end{array}$ & $\begin{array}{l}0.177^{*} \\
(0.081)\end{array}$ & & \\
\hline Ln(price) and medium-income interaction & & & & $\begin{array}{l}-0.058 \\
(0.054)\end{array}$ & $\begin{array}{l}-0.066 \\
(0.054)\end{array}$ & & \\
\hline Ln(price) and missing-income interaction & & & & $\begin{array}{l}0.126 \\
(0.107)\end{array}$ & $\begin{array}{l}0.093 \\
(0.104)\end{array}$ & & \\
\hline Ln(price) and less than high school interaction & & & & & & $\begin{array}{l}-0.029 \\
(0.121)\end{array}$ & $\begin{array}{l}-0.033 \\
(0.121)\end{array}$ \\
\hline Ln(price) and high school interaction & & & & & & $\begin{array}{l}0.023 \\
(0.046)\end{array}$ & $\begin{array}{l}0.027 \\
(0.046)\end{array}$ \\
\hline Female & $\begin{array}{l}-0.458^{* * *} \\
(0.049)\end{array}$ & $\begin{array}{l}-0.449^{* * *} \\
(0.049)\end{array}$ & $\begin{array}{l}-0.458^{* * *} \\
(0.049)\end{array}$ & $\begin{array}{l}-0.458^{* * *} \\
(0.049)\end{array}$ & $\begin{array}{l}-0.449 * * * \\
(0.049)\end{array}$ & $\begin{array}{l}-0.459 * * * \\
(0.049)\end{array}$ & $\begin{array}{l}-0.459^{* * *} \\
(0.049)\end{array}$ \\
\hline \multicolumn{8}{|l|}{ Male (reference category) } \\
\hline Aged 18-24 & $\begin{array}{l}-0.399 * * * \\
(0.093)\end{array}$ & $\begin{array}{l}-0.415^{* * *} \\
(0.091)\end{array}$ & $\begin{array}{l}-0.395^{* * *} \\
(0.093)\end{array}$ & $\begin{array}{l}-0.396^{* * *} \\
(0.092)\end{array}$ & $\begin{array}{l}-0.413^{* * *} \\
(0.090)\end{array}$ & $\begin{array}{l}-0.399 * * * \\
(0.093)\end{array}$ & $\begin{array}{l}-0.396^{* * *} \\
(0.093)\end{array}$ \\
\hline Aged 25-39 & $\begin{array}{l}-0.092^{* *} \\
(0.033)\end{array}$ & $\begin{array}{l}-0.108^{* *} \\
(0.033)\end{array}$ & $\begin{array}{l}-0.091 * * \\
(0.033)\end{array}$ & $\begin{array}{l}-0.090^{* *} \\
(0.033)\end{array}$ & $\begin{array}{l}-0.107^{* *} \\
(0.033)\end{array}$ & $\begin{array}{l}-0.091 \text { ** } \\
(0.033)\end{array}$ & $\begin{array}{l}-0.091^{* *} \\
(0.033)\end{array}$ \\
\hline Aged 40-54 & $\begin{array}{l}0.049 \\
(0.026)\end{array}$ & $\begin{array}{l}0.046 \\
(0.026)\end{array}$ & $\begin{array}{l}0.044 \\
(0.026)\end{array}$ & $\begin{array}{l}0.047 \\
(0.026)\end{array}$ & $\begin{array}{l}0.045 \\
(0.026)\end{array}$ & $\begin{array}{l}0.049 \\
(0.026)\end{array}$ & $\begin{array}{l}0.045 \\
(0.026)\end{array}$ \\
\hline \multicolumn{8}{|l|}{ Aged 55+ (reference category) } \\
\hline Divorced/widowed dummy & $\begin{array}{l}0.031 \\
(0.037)\end{array}$ & $\begin{array}{l}0.033 \\
(0.037)\end{array}$ & $\begin{array}{l}0.016 \\
(0.037)\end{array}$ & $\begin{array}{l}0.031 \\
(0.037)\end{array}$ & $\begin{array}{l}0.033 \\
(0.037)\end{array}$ & $\begin{array}{l}0.030 \\
(0.037)\end{array}$ & $\begin{array}{l}0.016 \\
(0.037)\end{array}$ \\
\hline Single dummy & $\begin{array}{l}-0.081 \\
(0.045)\end{array}$ & $\begin{array}{l}-0.089^{*} \\
(0.044)\end{array}$ & $\begin{array}{l}-0.090^{*} \\
(0.045)\end{array}$ & $\begin{array}{l}-0.083 \\
(0.045)\end{array}$ & $\begin{array}{l}-0.092^{*} \\
(0.044)\end{array}$ & $\begin{array}{l}-0.081 \\
(0.045)\end{array}$ & $\begin{array}{l}-0.090^{*} \\
(0.045)\end{array}$ \\
\hline \multicolumn{8}{|l|}{ Married dummy (reference category) } \\
\hline Low-income dummy & $\begin{array}{l}-0.088^{* *} \\
(0.033)\end{array}$ & $\begin{array}{l}-0.067^{*} \\
(0.032)\end{array}$ & & $\begin{array}{l}-0.411^{*} \\
(0.160)\end{array}$ & $\begin{array}{l}-0.382^{*} \\
(0.159)\end{array}$ & $\begin{array}{l}-0.088^{* *} \\
(0.033)\end{array}$ & \\
\hline Medium-income dummy & $\begin{array}{l}-0.052^{*} \\
(0.024)\end{array}$ & $\begin{array}{l}-0.036 \\
(0.024)\end{array}$ & & $\begin{array}{l}0.054 \\
(0.108)\end{array}$ & $\begin{array}{l}0.085 \\
(0.108)\end{array}$ & $\begin{array}{l}-0.052^{*} \\
(0.024)\end{array}$ & \\
\hline Missing-income dummy & $\begin{array}{l}-0.057 \\
(0.037)\end{array}$ & $\begin{array}{l}-0.047 \\
(0.037)\end{array}$ & & $\begin{array}{l}-0.292 \\
(0.210)\end{array}$ & $\begin{array}{l}-0.221 \\
(0.204)\end{array}$ & $\begin{array}{l}-0.056 \\
(0.037)\end{array}$ & \\
\hline \multicolumn{8}{|l|}{ High-income dummy (reference category) } \\
\hline Less than high school dummy & $\begin{array}{l}0.134^{* * *} \\
(0.041)\end{array}$ & & $\begin{array}{l}0.115^{* *} \\
(0.040)\end{array}$ & $\begin{array}{l}0.135^{* * *} \\
(0.041)\end{array}$ & & $\begin{array}{l}0.185 \\
(0.219)\end{array}$ & $\begin{array}{l}0.173 \\
(0.219)\end{array}$ \\
\hline High school dummy & $\begin{array}{l}0.111^{* * *} \\
(0.027)\end{array}$ & & $\begin{array}{l}0.098 * * * \\
(0.026)\end{array}$ & $\begin{array}{l}0.112^{* * *} \\
(0.027)\end{array}$ & & $\begin{array}{l}0.068 \\
(0.094)\end{array}$ & $\begin{array}{l}0.046 \\
(0.094)\end{array}$ \\
\hline \multicolumn{8}{|l|}{ College dummy (reference category) } \\
\hline Unemployed dummy & $\begin{array}{l}0.060^{*} \\
(0.026)\end{array}$ & $\begin{array}{l}0.071^{* *} \\
(0.027)\end{array}$ & $\begin{array}{l}0.043 \\
(0.025)\end{array}$ & $\begin{array}{l}0.061^{*} \\
(0.026)\end{array}$ & $\begin{array}{l}0.072^{* *} \\
(0.027)\end{array}$ & $\begin{array}{l}0.061^{*} \\
(0.026)\end{array}$ & $\begin{array}{l}0.044 \\
(0.025)\end{array}$ \\
\hline Retired dummy & $\begin{array}{l}-0.124^{* * *} \\
(0.027)\end{array}$ & $\begin{array}{l}-0.120^{* * *} \\
(0.027)\end{array}$ & $\begin{array}{l}-0.125^{* * *} \\
(0.027)\end{array}$ & $\begin{array}{l}-0.125^{* * *} \\
(0.027)\end{array}$ & $\begin{array}{l}-0.120 * * * \\
(0.026)\end{array}$ & $\begin{array}{l}-0.124^{* * *} \\
(0.027)\end{array}$ & $\begin{array}{l}-0.125^{* * *} \\
(0.027)\end{array}$ \\
\hline \multicolumn{8}{|l|}{ Employ dummy (reference category) } \\
\hline Constant & $\begin{array}{l}2.739 * * * \\
(0.050)\end{array}$ & $\begin{array}{l}2.837^{* * *} \\
(0.045)\end{array}$ & $\begin{array}{l}2.708^{* * *} \\
(0.051)\end{array}$ & $\begin{array}{l}2.740 * * * \\
(0.051)\end{array}$ & $\begin{array}{l}2.836^{* * *} \\
(0.046)\end{array}$ & $\begin{array}{l}2.742 * * * \\
(0.052)\end{array}$ & $\begin{array}{l}2.713^{* * *} \\
(0.052)\end{array}$ \\
\hline Observations & 13748 & 13785 & 13748 & 13748 & 13785 & 13748 & 13748 \\
\hline
\end{tabular}

SE in parentheses; interview wave and city dummies are not shown in the table.

${ }^{*} p<0.10,{ }^{* *} p<0.05,{ }^{* * *} p<0.01$.

urban Chinese smokers. In other words, while smokers do respond to a cigarette price increase by reducing the number of cigarettes smoked per day, those with low-level or medium-level education do not reduce their cigarette consumption more than those with high level of education, everything else being constant. These results also imply that, at least in our sample, smokers with medium-level income respond similarly to a cigarette price increase as those with high-level income. However, those with low-income level do not reduce the number of cigarettes smoked per day by as much as those smokers with medium- and high-level income, as shown by the positive coefficient on the price and low income interaction term.
Table 2 also reveals several additional interesting findings: female smokers smoke fewer cigarettes (approximately 36\% less) per day than male smokers. An age gradient in cigarette consumption exists among adult urban Chinese smokers: the numbers of cigarettes CPD were highest among those aged 40 years and above, lower among those aged 25-39 years (9\% fewer CPD than those among aged 40+ years) and lowest among young adults aged $18-24$ years (33\% fewer CPD than those among aged $40+$ years). Additionally, while smokers with low levels of income smoke fewer cigarettes per day ( $8 \%$ fewer) than their high-income counterparts (model 1), smokers with low- and medium-level education smoke more $(13 \%$ and $11 \%$ 
Table 3 Conditional cigarette consumption price elasticities among smokers by income groups

\begin{tabular}{|c|c|c|c|}
\hline & High-income subgroup & Medium-income subgroup & Low-income subgroup \\
\hline $\operatorname{Ln}($ price) & $\begin{array}{l}-0.150^{* * *} \\
(-0.206 \text { to }-0.094)\end{array}$ & $\begin{array}{l}-0.142^{* * *} \\
(-0.199 \text { to }-0.086)\end{array}$ & $\begin{array}{l}-0.111 \\
(-0.223 \text { to } 0.0002)\end{array}$ \\
\hline Female & $\begin{array}{l}-0.490^{* * *} \\
(-0.636 \text { to }-0.344)\end{array}$ & $\begin{array}{l}-0.446^{* * *} \\
(-0.586 \text { to }-0.307)\end{array}$ & $\begin{array}{l}-0.380^{* * *} \\
(-0.576 \text { to }-0.184)\end{array}$ \\
\hline \multicolumn{4}{|l|}{ Male (reference category) } \\
\hline Aged 18-24 & $\begin{array}{l}-0.463^{* *} \\
(-0.747 \text { to }-0.179)\end{array}$ & $\begin{array}{l}-0.435^{* * *} \\
(-0.677 \text { to }-0.193)\end{array}$ & $\begin{array}{l}-0.485^{* *} \\
(-0.817 \text { to }-0.154)\end{array}$ \\
\hline Aged 25-39 & $\begin{array}{l}-0.137^{* *} \\
(-0.234 \text { to }-0.040)\end{array}$ & $\begin{array}{l}-0.080 \\
(-0.182 \text { to } 0.022)\end{array}$ & $\begin{array}{l}-0.124 \\
(-0.279 \text { to } 0.031)\end{array}$ \\
\hline Aged 40-54 & $\begin{array}{l}-0.0258 \\
(-0.108 \text { to } 0.056)\end{array}$ & $\begin{array}{l}0.093^{*} \\
(0.016 \text { to } 0.170)\end{array}$ & $\begin{array}{l}0.045 \\
(-0.068 \text { to } 0.157)\end{array}$ \\
\hline \multicolumn{4}{|c|}{ Aged 55+ (reference category) } \\
\hline Divorce/widowed dummy & $\begin{array}{l}0.097 \\
(-0.043 \text { to } 0.236)\end{array}$ & $\begin{array}{l}0.022 \\
(-0.084 \text { to } 0.128)\end{array}$ & $\begin{array}{l}-0.033 \\
(-0.177 \text { to } 0.110)\end{array}$ \\
\hline Single dummy & $\begin{array}{l}-0.114 \\
(-0.244 \text { to } 0.016)\end{array}$ & $\begin{array}{l}0.034 \\
(-0.135 \text { to } 0.203)\end{array}$ & $\begin{array}{l}0.046 \\
(-0.097 \text { to } 0.189)\end{array}$ \\
\hline \multicolumn{4}{|c|}{ Married dummy (reference category) } \\
\hline Less than HS dummy & $\begin{array}{l}0.136^{*} \\
(0.017 \text { to } 0.254)\end{array}$ & $\begin{array}{l}0.166^{*} \\
(0.035 \text { to } 0.298)\end{array}$ & $\begin{array}{l}0.029 \\
(-0.221 \text { to } 0.279)\end{array}$ \\
\hline High school dummy & $\begin{array}{l}0.119^{* * *} \\
(0.051 \text { to } 0.186)\end{array}$ & $\begin{array}{l}0.132^{* *} \\
(0.037 \text { to } 0.227)\end{array}$ & $\begin{array}{l}0.040 \\
(-0.175 \text { to } 0.255)\end{array}$ \\
\hline \multicolumn{4}{|c|}{ College dummy (reference category) } \\
\hline Unemployed dummy & $\begin{array}{l}0.098 \\
(-0.046 \text { to } 0.242)\end{array}$ & $\begin{array}{l}0.033 \\
(-0.040 \text { to } 0.106)\end{array}$ & $\begin{array}{l}0.085 \\
(-0.006 \text { to } 0.176)\end{array}$ \\
\hline Retired dummy & $\begin{array}{l}-0.204^{* * *} \\
(-0.291 \text { to }-0.117)\end{array}$ & $\begin{array}{l}-0.103^{*} \\
(-0.183 \text { to }-0.024)\end{array}$ & $\begin{array}{l}-0.096 \\
(-0.226 \text { to } 0.033)\end{array}$ \\
\hline \multicolumn{4}{|c|}{ Employed dummy (reference category) } \\
\hline Constant & $\begin{array}{l}2.918^{* * *} \\
(2.756 \text { to } 3.081)\end{array}$ & $\begin{array}{l}2.653^{* * *} \\
(2.494 \text { to } 2.813)\end{array}$ & $\begin{array}{l}2.652^{* * *} \\
(2.237 \text { to } 3.066)\end{array}$ \\
\hline Observations & 4941 & 5893 & 2042 \\
\hline
\end{tabular}

$95 \% \mathrm{Cl}$ in parentheses; interview wave and city dummies are not shown in the table.

${ }^{*} p<0.10,{ }^{* *} p<0.05,{ }^{* * *} p<0.01$.

more CPD, respectively) cigarettes per day than smokers with postsecondary education, everything else being the same. Moreover, smokers who were unemployed at the time of the survey reported smoking more $(6 \%)$ cigarettes per day than those who were employed, while smokers who were retired reported smoking fewer (11\%) cigarettes per day.

Table 3 presents the GEE estimates from the subsample analyses by income levels based on equation (1). While the estimated price elasticities for high-income and medium-income smokers were similar in magnitude (in a narrow range of -0.14 to -0.15$)$ and statistically significant, the estimated price elasticity for low-income smokers did not statistically differ from 0 , meaning that low-income smokers do not significantly reduce their cigarette consumption when cigarette price increases, at least among those who continue to smoke. This result mirrors the results from table 2 (model 4 and 5). Similarly, many of the results from the subsample analyses related to the association between the demographic and SES factors, and cigarette consumption, mirror those based on the entire sample: fewer CPD among female smokers, an age gradient in CPD, and higher consumption among smokers with low-level and medium-level education, although not all these results were statistically significant in all subsamples.

The results from the analyses based on education subsamples were presented in table 4 . Across all three education levels, the estimated conditional cigarette consumption price elasticities were statistically significant. The magnitude of the estimated price elasticity range from -0.11 to -0.14 , with the $95 \%$ CIs overlapping across three education levels, consistent with the results from model 6 and 7 in table 2. Regardless of the education level, female smokers consume fewer cigarettes per day than their male counterparts. Compared to other age groups, young adults smoke fewer cigarettes per day regardless of education levels.

\section{CONCLUSION AND DISCUSSION}

Our analysis of the ITC China Survey data reveals that the overall conditional cigarette demand price elasticity ranges from -0.12 to -0.14 , implying a $10 \%$ increase in cigarette price would result in a reduction in cigarette consumption among adult urban Chinese smokers by $1.2-1.4 \%$. Relative to many other low-income and middle-income countries, our results suggest that cigarette consumption among Chinese adult smokers is not very sensitive to changes in cigarette prices. Compared to the estimates of the price elasticity of demand for cigarettes in China from previous studies, which range from 0 to $-0.8,,^{9-17}$ our estimates are at the lower end (in absolute value), and are similar to the results from two recent studies using national representative individual level cross-sectional data. ${ }^{13}{ }^{15}$ However, please note that our study only considered the impact of a cigarette price increase on those who continued to smoke. It left out the impact of a cigarette price increase on deterring youth smoking initiation and promoting quitting among smokers. Studies have shown that the impact of a cigarette price increase on smoking initiation and cessation could be just as large as the impact on cigarette consumption among 
Table 4 Conditional cigarette consumption price elasticities among smokers by education groups

\begin{tabular}{|c|c|c|c|}
\hline & High-education subgroup & $\begin{array}{l}\text { Medium-education subgroup } \\
\text { (high school) }\end{array}$ & $\begin{array}{l}\text { Low-education subgroup } \\
\text { (less than high school) }\end{array}$ \\
\hline $\operatorname{Ln}$ (price) & $\begin{array}{l}-0.113^{* *} \\
(-0.182 \text { to }-0.045)\end{array}$ & $\begin{array}{l}-0.107^{* * *} \\
(-0.155 \text { to }-0.059)\end{array}$ & $\begin{array}{l}-0.143^{*} \\
(-0.257 \text { to }-0.030)\end{array}$ \\
\hline Female & $\begin{array}{l}-0.375^{* *} \\
(-0.617 \text { to }-0.133)\end{array}$ & $\begin{array}{l}-0.550^{* * *} \\
(-0.676 \text { to }-0.424)\end{array}$ & $\begin{array}{l}-0.352^{* * *} \\
(-0.515 \text { to }-0.189)\end{array}$ \\
\hline \multicolumn{4}{|l|}{ Male (reference category) } \\
\hline Aged 18-24 & $\begin{array}{l}-0.414^{* *} \\
(-0.669 \text { to }-0.160)\end{array}$ & $\begin{array}{l}-0.444^{* * *} \\
(-0.683 \text { to }-0.205)\end{array}$ & $\begin{array}{l}-0.243^{*} \\
(-0.468 \text { to }-0.017)\end{array}$ \\
\hline Aged 25-39 & $\begin{array}{l}-0.178^{* *} \\
(-0.310 \text { to }-0.046)\end{array}$ & $\begin{array}{l}-0.058 \\
(-0.134 \text { to } 0.017)\end{array}$ & $\begin{array}{l}-0.005 \\
(-0.245 \text { to } 0.236)\end{array}$ \\
\hline Aged 40-54 & $\begin{array}{l}0.0171 \\
(-0.104 \text { to } 0.138)\end{array}$ & $\begin{array}{l}0.058 \\
(-0.003 \text { to } 0.118)\end{array}$ & $\begin{array}{l}0.003 \\
(-0.144 \text { to } 0.149)\end{array}$ \\
\hline \multicolumn{4}{|c|}{ Aged 55+ (reference category) } \\
\hline Divorce/widowed dummy & $\begin{array}{l}0.139 \\
(-0.050 \text { to } 0.329)\end{array}$ & $\begin{array}{l}0.016 \\
(-0.067 \text { to } 0.099)\end{array}$ & $\begin{array}{l}-0.007 \\
(-0.161 \text { to } 0.147)\end{array}$ \\
\hline Single dummy & $\begin{array}{l}-0.142^{*} \\
(-0.274 \text { to }-0.011)\end{array}$ & $\begin{array}{l}-0.024 \\
(-0.131 \text { to } 0.084)\end{array}$ & $\begin{array}{l}-0.177 \\
(-0.648 \text { to } 0.294)\end{array}$ \\
\hline \multicolumn{4}{|c|}{ Married dummy (reference category) } \\
\hline Low-income dummy & $\begin{array}{l}-0.132 \\
(-0.374 \text { to } 0.110)\end{array}$ & $\begin{array}{l}-0.065 \\
(-0.142 \text { to } 0.013)\end{array}$ & $\begin{array}{l}-0.110 \\
(-0.242 \text { to } 0.021)\end{array}$ \\
\hline Medium-income dummy & $\begin{array}{l}-0.136^{*} \\
(-0.252 \text { to }-0.021)\end{array}$ & $\begin{array}{l}-0.039 \\
(-0.097 \text { to } 0.019)\end{array}$ & $\begin{array}{l}-0.071 \\
(-0.186 \text { to } 0.045)\end{array}$ \\
\hline Missing-income dummy & $\begin{array}{l}-0.041 \\
(-0.209 \text { to } 0.127)\end{array}$ & $\begin{array}{l}-0.062 \\
(-0.143 \text { to } 0.020)\end{array}$ & $\begin{array}{l}-0.026 \\
(-0.182 \text { to } 0.129)\end{array}$ \\
\hline \multicolumn{4}{|c|}{ High-income dummy (reference category) } \\
\hline Unemployed dummy & $\begin{array}{l}0.173^{*} \\
(0.026 \text { to } 0.320)\end{array}$ & $\begin{array}{l}0.045 \\
(-0.011 \text { to } 0.101)\end{array}$ & $\begin{array}{l}0.050 \\
(-0.091 \text { to } 0.191)\end{array}$ \\
\hline Retired dummy & $\begin{array}{l}-0.130 \\
(-0.278 \text { to } 0.019)\end{array}$ & $\begin{array}{l}-0.114^{* * *} \\
(-0.181 \text { to }-0.047)\end{array}$ & $\begin{array}{l}-0.137^{*} \\
(-0.251 \text { to }-0.023)\end{array}$ \\
\hline \multicolumn{4}{|l|}{ Employed dummy } \\
\hline Constant & $\begin{array}{l}2.736 * * * \\
(2.530 \text { to } 2.941)\end{array}$ & $\begin{array}{l}2.823^{* * *} \\
(2.719 \text { to } 2.927)\end{array}$ & $\begin{array}{l}2.932 * * * \\
(2.686 \text { to } 3.178)\end{array}$ \\
\hline Observations & 3070 & 9060 & 1618 \\
\hline
\end{tabular}

smokers, if not larger. ${ }^{8}$ As such, the total impact of cigarette price increases in China could be at least twice as large as what our estimates suggest. Additionally, several recent studies show that large cigarette price spreads across brands in China were associated with brand switching behaviour, and that increasing cigarette price may also lead to trading down among smokers for low quality and high-tar cigarettes. ${ }^{11}{ }^{19-21}$ Our estimates did not take into account the impact of brand switching and trading down, absence of such behaviours, our estimates would become larger.

Our results also revealed several important and interesting patterns related to the potential differential price impact by SES among Chinese smokers. We found that smokers with no high school qualification and with only a high school qualification smoke more cigarettes per day than those with postsecondary education. However, the estimated price elasticity of demand does not differ across education levels. In other words, when cigarette price increases, smokers across all education levels reduce their cigarette consumption equally. Additionally, we found that smokers with low-income and medium-income, smoke fewer cigarettes than their high-income counterparts. When cigarette price increases, high-income and medium-income smokers reduce their cigarette consumption. However, low-income smokers, at least among those who continue to smoke, did not seem to reduce their cigarette consumption after the price increase. Our finding that low-income smokers' cigarette consumption was less sensitive to price changes differs from the results from two previous studies, which found the opposite. ${ }^{16} 17$ There are at least two reasons that might explain this difference. First, our study did not look at the impact of price increase on smoking cessation. If lowincome smokers respond to a price increase primarily through quitting rather than cutting down cigarette consumption, by only looking at those who continue to smoke after the price increase, our analyses left out those who quit smoking and hence underestimated the true impact of a price increase on low-income smokers. Second, two recent studies have shown that low-income Chinese smokers are more likely to engage in behaviours that reduce the price paid for purchasing cigarettes, such as switching to a cheaper brand. ${ }^{19}{ }^{21}$ Brand switching can enable low-income smokers to maintain the same level of consumption, even when the average cigarette price increases. Because our analyses did not take into account the impact of such behaviour, our estimates likely underestimate the impact of cigarette price for low-income smokers. Consequently, the evidence presented in our study is, unfortunately, not sufficient to draw a clear conclusion on the regressivity of tobacco taxes in China. While we have shown that the conditional price elasticity on cigarette consumption is smaller among low-income smokers, the overall price elasticity of demand for cigarettes could be larger for low-income smokers than for high-income and middle-income smokers in China, if 
the price impact on initiation and cessation were taken into account and/or if the opportunities for cost-minimising behaviours were reduced.

In addition to the limitations discussed in the previous paragraphs, the representativeness and generalisation of our findings is also limited by the fact that our smoker sample covers only seven cities in China, and is older than the general adult smoker population in China.

Despite these limitations, our analyses provided evidence that cigarette consumption among Chinese adult urban smokers is sensitive to changes in cigarette prices. Smokers smoke fewer cigarettes after price increases, and the reduction in cigarette consumption was similar across all education levels. More research, however, is needed to examine the impact of cigarette price increase on smoking initiation among youth and long-term successful cessation among smokers in China. The results from our study also have important policy implications: first, to the extent that the availability of a wide range of low-cost cigarette brands, and the existence of brand switching and trading down behaviours, may play a role in moderating the impact of a price increase, particularly among low-income smokers, the results from our study suggest that a tobacco tax and price policy with a heavy specific tax component could have more beneficial impact in China, as an increase in a specific tax would raise the price of cheaper brands relative to premium brands to a greater extent than would an ad valorem tax. In addition, minimum price laws that prevent cigarette retail prices from falling below a threshold price regardless of brand could also be an effective policy tool to reduce cigarette consumption in China by discouraging brand switching and trading down.

\section{What the paper adds}

- This is the first study to use individual level multiwave longitudinal data to examine the impact of cigarette prices on cigarette consumption in China, and to look at whether there are potential differential responses to cigarette price increases based on socioeconomic status.

- We estimated that the conditional cigarette demand price elasticity ranges from -0.12 to -0.14 among adult urban Chinese smokers. Taking into account the price impact on smoking initiation and cessation, and price-reducing behaviour, could increase the magnitude of cigarette price elasticity.

Contributors JH, FJC, RZ and GTF designed the study; GTF and YJ collected data; $\mathrm{JH}$ conducted data analysis; JH, RZ and FJC contributed to data interpretation; $J H$ wrote the first draft; JH, RZ, FJC and GTF revised the draft; The final version of this paper has been reviewed and approved by all co-authors.

Funding The ITC China Project was supported by grants from the US National Cancer Institute at the National Institutes of Health (R01 CA100362, R01 CA125116 and P01 CA138389); the Roswell Park Transdisciplinary Tobacco Use Research Center (P50 CA111236); Robert Wood Johnson Foundation (045734); Canadian Institutes for Health Research (57897, 79551 and 115016); and Chinese Center for Disease Control and Prevention. Additional support was provided to Geoffrey T Fong from a Senior Investigator Award from the Ontario Institute for Cancer Research and a Prevention Scientist Award from the Canadian Cancer Society
Research Institute. Rong Zheng and Jidong Huang were supported by a grant from the Canadian International Development Research Centre (Grant Number 106839-001), titled "Impact of Tobacco Tax and Price Policies on Tobacco Use in China", and a grant from the China National Nature Science Foundation (Grant Number 71373045), titled "An Empirical Study and Policy Evaluation of China Tobacco Tax System and Tobacco Control". None of the funding agencies played any role in study design; in the collection, analysis and interpretation of data; in the writing of the report; or in the decision to submit the article for publication. The opinions expressed here are those of the authors, and do not necessarily reflect those of the sponsors.

\section{Competing interests None declared.}

\section{Patient consent Obtained.}

Ethics approval The ITC China Surveys were cleared for ethics by Research Ethics Boards or International Review Boards at the University of Waterloo (Canada), Roswell Park Cancer Institute (US), and the Chinese Centers of Disease Control and Prevention.

Provenance and peer review Not commissioned; externally peer reviewed.

\section{REFERENCES}

1 Jin SG, Lu BY, Yan DY, et al. An evaluation on smoking-induced health costs in China (1988-1989). Biomed Environ Sci 1995;8:342-9.

2 Peto R, Lopez AD. Future worldwide health effects of current smoking patterns. In: C. Everett Koop, Ed. Critical Issues in Global Health. San Francisco: Jossey-Bass, 2001, pp 154-61.

3 Peto R, Britain ICRF Great, Organization WH. Mortality from smoking in developed countries, 1950-2000: indirect estimates from national vital statistics. Oxford University Press, 1995.

4 Sung $\mathrm{H}$, Wang $\mathrm{L}$, Jin $\mathrm{S}$, et al. Economic burden of smoking in China, 2000. Tob Control 2006;15:i5-i11.

5 Yang L, Sung H-Y, Mao Z, et al. Economic costs attributable to smoking in China: update and an 8-year comparison, 2000-2008. Tob Control 2011;20:266-72.

6 Dan X, Yuankai S, Chen W. Tobacco in China. Lancet 2014;383:2045-6.

7 Jha P, Chaloupka F. Tobacco control in developing countries. 1st edn. USA: Oxford University Press, 2000.

8 International Agency for Research on Cancer. IARC Handbooks of Cancer Prevention, Tobacco Control, Vol. 14. Effectiveness of Tax and Price Policies for Tobacco Control. Lyon, France: 2011.

9 Hu T, Mao Z, Shi J, et al. The role of taxation in tobacco control and its potential economic impact in China. Tob Control 2010;19:58-64.

10 Bai Y, Zhang Z. Aggregate cigarette demand and regional differences in China. Appl Econ 2005;37:2523-8.

11 Chen Y, Xing W. Quantity, quality, and regional price variation of cigarettes: demand analysis based on a household survey in China. China Economic Review 2011;22:221-32.

$12 \mathrm{Hu}$ TW, Mao Z. Effects of cigarette tax on cigarette consumption and the Chinese economy. Tob Control 2002;11:105-8.

13 Lance PM, Akin JS, Dow WH, et al. Is cigarette smoking in poorer nations highly sensitive to price? Evidence from Russia and China. J Health Econ 2004;23:173-89.

14 Liu H, Rizzo JA, Sun Q, et al. How do smokers respond to cigarette taxes? evidence from China's cigarette industry. Health Econ. Published Online First: 18 July 2014. doi:10.1002/hec.3084

15 Mao Z, Hu T, Yang G. New estimate of the demand for cigarettes in China. Chinese $J$ Health Econ 2005;24:45-47.

16 Mao Z, Hu T, Yang G. Price elasticities and impact of tobacco tax among various income groups. Chinese J Evid-Based Med 2005:291-5.

17 Mao Z, Yang G, Ma H. Adults' demand for cigarettes and its determinants in China. Soft Sci Health 2003;17:19-23.

18 Wu C, Thompson ME, Fong GT, et al. Methods of the International Tobacco Control (ITC) China Survey. Tob Control 2010;19(Suppl 2):i1-5.

19 Huang J, Zheng R, Chaloupka FJ, et al. Chinese smokers' cigarette purchase behaviours, cigarette prices and consumption: findings from the ITC China Survey. Tob Control 2014;23(Suppl 1):i67-72.

20 Yao T, Huang J, Sung H-Y, et al. Who purchases cigarettes from cheaper sources in China? Findings from the ITC China Survey. Tob Control 2014;23(Suppl 1):i97-101.

21 White JS, Li J, Hu T, et al. The effect of cigarette prices on brand-switching in China: a longitudinal analysis of data from the ITC China Survey. Tob Control 2014;23(Suppl 1):i54-60. 